\title{
Retraction Note to: The stability of rainfall conditions based on sensor networks and the effect of psychological intervention for patients with urban anxiety disorder
}

\section{Zhiping Jia ${ }^{1}$}

Published online: 3 November 2021

(c) Saudi Society for Geosciences 2021

Retraction Note to: Arabian Journal of Geosciences (2021) 14: 1753 https://doi.org/10.1007/s12517-021-08087-y

The Editor-in-Chief and the Publisher have retracted this article because the content of this article is nonsensical. The peer review process was not carried out in accordance with the Publisher's peer review policy. The author has not responded to correspondence regarding this retraction.

The original article can be found online at https://doi.org/10.1007/ s12517-021-08087-y.

Zhiping Jia

jzp45601@126.com

1 Hebei Chemical \& Pharmaceutical College, Shijiazhuang 050026, Hebei, China 